Felix Wilhelm Siebert, Deike Albers, U Aung Naing, Paolo Perego, Chamaiparn Santikarn

\title{
Patterns of motorcycle helmet use - A naturalistic observation study in Myanmar
}

Journal article | Accepted manuscript (Postprint)

This version is available at http://dx.doi.org/10.14279/depositonce-8784

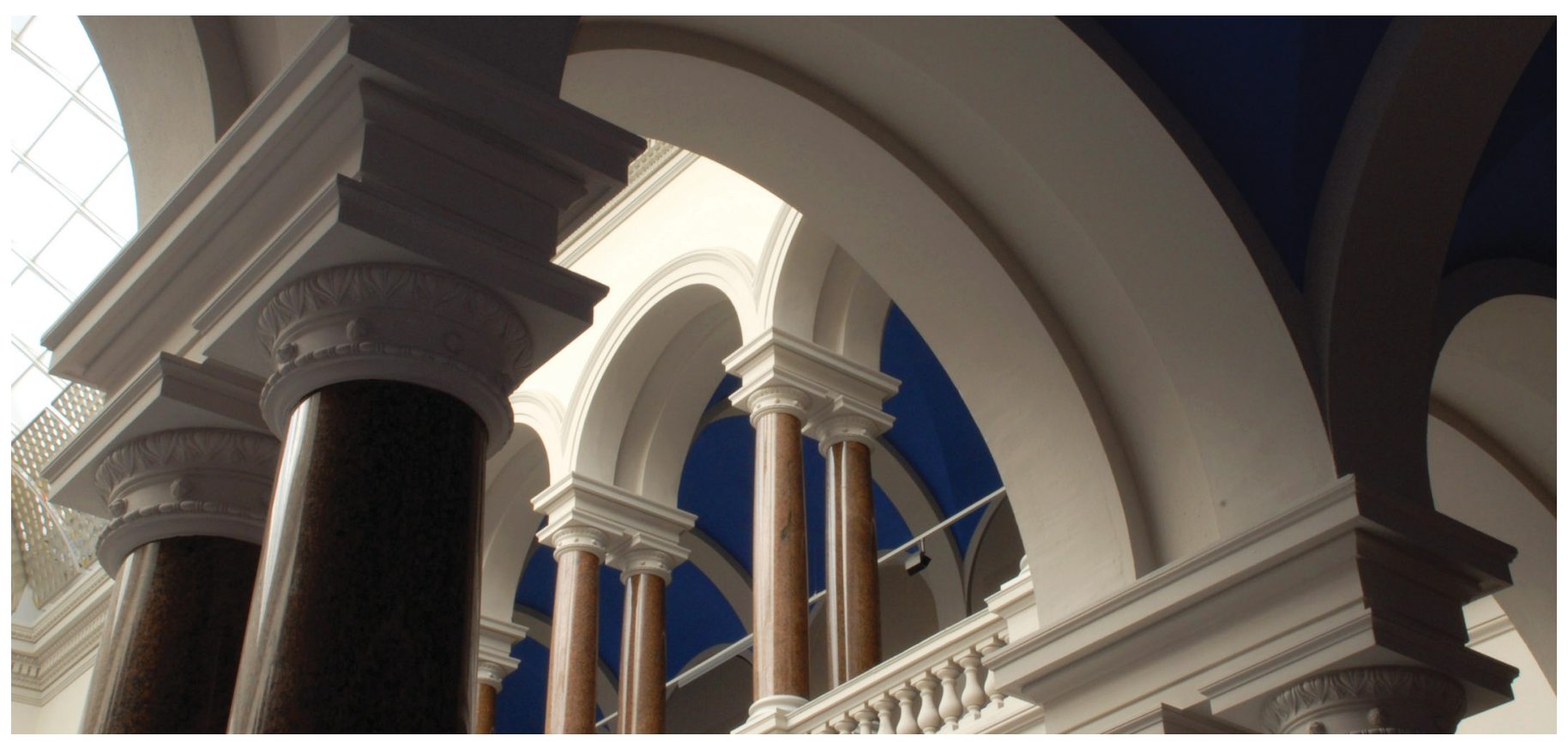

Siebert, F. W., Albers, D., Naing, U. A., Perego, P., \& Santikarn, C. (2019). Patterns of motorcycle helmet use - A naturalistic observation study in Myanmar. Accident Analysis \& Prevention, 124, 146-150. https://doi.org/10.1016/j.aap.2019.01.011 
This is the Accepted Manuscript of the following article published by Elsevier in Accident Analysis \& Prevention [11. January 2019]:

Siebert, F. W., Albers, D., Naing, U. A., Perego, P., \& Santikarn, C. (2019). Patterns of motorcycle helmet use-A naturalistic observation study in Myanmar. Accident Analysis \& Prevention, 124, 146150. https://doi.org/10.1016/j.aap.2019.01.011

This manuscript is not the copy of record and may not exactly replicate the final, authoritative version of the article.

This work is licensed under a Creative Commons Attribution-NonCommercial-NoDerivatives 4.0 International License, http://creativecommons.org/licenses/by-nc-nd/4.0/. 


\section{Patterns of motorcycle helmet use - a naturalistic observation study in Myanmar}

Felix Wilhelm Siebert*a ${ }^{*}$ Deike Albers ${ }^{\mathrm{b}}, \mathrm{U}^{\mathrm{A}}$ Aung Naing ${ }^{\mathrm{c}}$, Paolo Perego $^{\mathrm{d}}$, \& Chamaiparn Santikarn $^{\mathrm{e}}$

* Corresponding Author

${ }^{\text {a }}$ Department of Psychology and Ergonomics, Technische Universität Berlin, Marchstraße 12, 10587 Berlin, Germany, felix.siebert@tu-berlin.de

${ }^{\mathrm{b}}$ Technical University of Munich, Arcisstraße 21, 80333 Munich, Germany, deike.albers@tum.de

${ }^{\mathrm{c}}$ Myanmar Organization for Road Safety, People's Park, U Wisara Road, Yangon, Myanmar, info@mors2015.org

${ }^{\mathrm{d}}$ Catholic University of Milan, Largo Agostino Gemelli, 1, 20123 Milan, Italy, psicotraffico@unicatt.it

e World Health Organization, No. 403, Shwe Taung Kyar Street, 11201 Yangon, Myanmar, santikarnc@who.int 


\section{ABSTRACT}

Developing countries are subject to increased motorization, particularly in the number of motorcycles. As helmet use is critical to the safety of motorcycle riders, the goal of this study was to identify observable patterns of helmet use, which allow a more accurate assessment of helmet use in developing countries. In a video based observation study, 124,784 motorcycle riders were observed at seven observation sites throughout Myanmar. Recorded videos were coded for helmet use, number of riders on the motorcycle, rider position, gender, and time of day. Generally, motorcycle helmet use in Myanmar was found to be low with only $51.5 \%$ percent of riders wearing a helmet. Helmet use was highest for drivers (68.1\%) and decreased for every additional passenger. It was lowest for children standing on the floorboard of the motorcycle (11.3\%). During the day, helmet use followed a unimodal distribution, with the highest use observed during the late morning and lowest use observed in the early morning and late afternoon. Helmet use varied significantly between observation sites, ranging from 74.8\% in Mandalay to $26.9 \%$ in Pakokku. In Mandalay, female riders had a higher helmet use than male riders, and helmet use decreased drastically on a national holiday in the city. Helmet use of motorcycle riders in Myanmar follows distinct patterns. Knowledge of these patterns can be used to design more precise helmet use evaluations and guide traffic law policy and police enforcement measures. Video based observation proved to be an efficient tool to collect helmet use data.

Keywords: motorcycle; helmet use; naturalistic observation; developing countries 


\section{INTRODUCTION}

Road traffic crashes cause 1.2 million fatalities and more than 75 million non-fatal injuries each year and are the leading cause of death for young people between 15 and 29 years (Vos et al., 2017; World Health Organization, 2015). A disproportionately high share of road traffic fatalities occurs in low- and middle-income countries, an imbalance that is even more striking in the light of their relatively small number of registered motorized vehicles compared to high-income countries (World Health Organization, 2015). An increasing motorization in developing countries is projected to aggravate this problem (Nantulya \& Reich, 2002; Peden, 2004; Vos et al., 2017). To engage this global road safety challenge, the United Nations have proclaimed the Decade of Action for Road Safety and established the Sustainable

Development Goals, to support measures that can reduce road traffic related fatalities and injuries (United Nations, 2010; United Nations, 2015). The World Health Organization (WHO) is actively supporting this process by tracking key factors of progress in the Decade of Action for Road Safety through the publication of the Global Status Report on Road Safety (GSRRS) (World Health Organization, 2015). One of the factors contributing to the high number of road traffic fatalities in low- and middle- income countries is their high share of so called vulnerable road users (VRU), i.e. pedestrians, bicyclists, and motorcyclists who lack an “outer protective cell” and are therefore vulnerable in case of a collision (Otte, Jänsch, \& Haasper, 2012; World Health Organization, 2015).

Motorcyclists represent an especially vulnerable subgroup of VRU, as they sustain the most severe injuries due to their relatively high speed. However, this prevalence for severe injuries can be mitigated by using motorcycle helmets (Otte et al., 2012; World Health Organization, 2006; World Health Organization, 2017). Helmets can lower the risk of fatal injuries of riders by $42 \%$ and reduce the risk of head injury by $69 \%$ (Liu et al., 2004). It is therefore of great importance to collect detailed data about motorcycle helmet use, especially in countries with a 
high share of motorcycle traffic. Detailed data allows governments to better assess the status of road safety in their country and makes possible targeted helmet specific interventions through police enforcement or traffic laws. To support governments in this area, the GSRRS lists the average helmet use rate for motorcycle riders for individual countries. Since its newest iteration the GSRRS also provides helmet use averages separately for drivers and passengers if this data is available. Although the importance of motorcycle helmet use in preventing road traffic fatalities is well known, helmet use is only reported for $33.6 \%$ of lowand middle income countries in the GSRRS, since a majority of countries does not collect detailed information about motorcycle helmet use (World Health Organization, 2015). The available data on motorcycle helmet use in the GSRRS shows that it is highest in high-income countries (89\%), followed by helmet use in middle income countries $(52.3 \%)$ and low-income countries $(31.7 \%)$. This study has the goal to a) presents a method for collecting motorcycle helmet use data with limited resources that can be easily applied in low- and middle-income countries and b) identify observable patterns in helmet use that can guide road safety policy and police enforcement activities and can be used to increase the accuracy of future helmet use evaluations.

Myanmar was chosen as the place for this study, as it shares common characteristics with other countries in the low- and middle income range, i.e. it has a high share of motorcycle traffic and the number of motorcycles is increasing (Wegman, Watson, Wong, Job, SeguiGomez, 2017). Myanmar has seen a rapid increase in general motorized traffic, which mostly stems from a surge in registered motorcycles which increased more than sevenfold from only 655,000 in 2007 to more than 4.7 million in 2016. In the same amount of time, the number of registered passenger cars (including taxis) has only increased moderately from 224,000 in 2007 to 505,000 in 2016 (Myanmar Road Transport Administration Department, 2016). By law, all motorcycle riders in Myanmar are required to wear a helmet and close the chin-strap (fine up to 30,000 Myanmar Kyat ( 22US\$)) (Assembly of the Union of Myanmar, 2015). In 
2015 the WHO estimated that close to 11,000 people die every year in Myanmar due to road traffic crashes, a number that translates to 20.3 road traffic fatalities per 100.000 population (World Health Organization, 2015). Due to the increasing motorization of the country, road safety experts estimate that the number of fatalities will increase further in the coming years (Wegman et al., 2017). Myanmar is exemplary for other developing countries in that data on motorcycle helmet use is not collected by the government regularly, and that no detailed data on helmet use is available from other sources. The most recent study of helmet use in Myanmar was conducted by the Yangon General hospital in 2011, where helmet use was estimated to be between $48-51 \%$ for all riders (i.e. drivers and passengers) (World Health Organization, 2015). No information is available on the methodology, estimated cost, or sample size used to arrive at this estimate.

\subsection{Factors influencing helmet use}

A number of factors that influence individual use of safety equipment in traffic have been identified. Researchers have found that theories such as the Health Belief Model, Locus of Control, and the Theory of Planned Behavior can help to explain why riders use motorcycle helmets (Aghamolaei, Tavafian, \& Madani, 2011, Özkan, Lajunen, Doğruyol, Yıldırım, \& Çoymak, 2012). Social norms and attitudes towards helmet use have also been found to have an influence on use rates (Bachani et al., 2013; Haqverdi, Seyedabrishami, Groeger, 2015; Li, Li, Cai, Zhang, \& Lo, 2008). Since this study uses an observation based data collection framework, subjective variables that could potentially help to explain variance in helmet use were not assessed. Thus, this study focused on easily observable individual and environmental factors that may have an influence on helmet use, i.e. number and position of riders on the motorcycle, gender, and time of day.

On an individual level, studies have found significant differences in helmet use between drivers and passengers, as drivers are more likely to use a helmet than passengers (Bachani et 
al., 2012; Hung, Stevenson, \& Ivers, 2006; Oxley, O’Hern, \& Jamaludin, 2018). Due to these differences, helmet use is listed separately for drivers and passengers for some of the countries in the GSRRS, with the goal to paint a more accurate picture of helmet use in a given country (World Health Organization, 2015). In a review of helmet use studies conducted Southeast Asian countries, Peltzer \& Pengpid (2014) found that motorcycle helmet use varies widely within countries. Mathur, Gupta, and Bandhu (2017) found that helmet use can vary broadly even on a state level. The high variance in helmet use underscores the importance of conducting helmet use assessments at a number of observation sites within a given country.

Another individual factor that has been observed to influence motorcycle helmet use is the gender of riders. Studies find that female riders are more likely to use helmets than male riders, e.g. in China (Li et al., 2008; Xuequn, Ke, Ivers, Du, \& Senserrick, 2011) or Greece (Skalkidou, Petridou, Papadopoulos, Dessypris, \& Trichopoulos, 1999). An opposing effect has been observed in Vietnam, where male drivers are more likely to use a helmet compared to female drivers, although this effect reverses for passengers (Hung et al., 2006). The time of day during the helmet use observation has also been shown to significantly influence motorcycle helmet use, as helmet use decreases in the evening and at night (Ichikawa, Chadbunchachai, \& Marui, 2003; Li et al., 2008; Nakahara, Chadbunchachai, Ichikawa, Tipsuntornsak, \& Wakai, 2005; Skalkidou et al., 1999). In the light of past research on helmet use, the observable factors of number of riders on the motorcycle, position of riders, gender, and time of day where included and coded in the helmet use observations during this study. 


\section{METHOD}

In July and August 2016 motorcycle helmet use was recorded at seven observation sites throughout Myanmar in a collaborative effort by the Myanmar Organization for Road Safety, the Myanmar Traffic Police Force, the Leuphana University Lüneburg, and the Technical University of Berlin with technical advice by the WHO Country Office professional staff. Naturalistic observation was used as it generates the most accurate data on rider behavior (Eby, 2011). Observation sites were selected to represent different city sizes, and for their accessibility and the availability of traffic police support. Details about the observation sites can be found in Table 1. At each observation site, traffic was recorded with two traffic observation cameras built from off the shelf components. The resolution of the recorded videos was 1920x1080 pixels with a recording rate of ten frames per second. Traffic was recorded between 06:00am and 06:30pm (during daylight hours) for two consecutive days in each city. The two cameras were installed at lampposts on the roadside at an approximate height of $2.5 \mathrm{~m}$. In one city (Mandalay), traffic was filmed for seven consecutive days in order to compare helmet use during a national holiday to helmet use during the remainder of the week. A total of 385 hours of traffic were recorded. The open source event-logging software BORIS (Behavioral Observation Research Interactive Software) was used to code helmet use of drivers and passengers of motorcycles (Friard, \& Gamba, 2016). To reduce coding workload, only the first 15 minutes of every hour were analyzed, resulting in 103 hours of coded helmet use. While the time of day, weekday, and observation site location were set once or coded automatically, helmet use (helmet, no helmet, not recognized) and number and position of riders on the motorcycle for all recordings were coded by hand. For the position, all passengers behind the driver were coded consecutively (passenger [1, 2, 3]), while children standing in front of the driver on the floorboard of the motorcycle were coded as "passenger 0" (see Figure 1). Gender (female, male, not recognized) was coded by hand for only one day of 
observation in Mandalay to keep the coding workload manageable. Use of the helmet's chinstrap, as well as helmet quality were not coded.

\section{RESULTS}

In total, the helmet use of 124,784 motorcycle riders was coded. Countrywide helmet use in Myanmar, as observed in our study and calculated by averaging helmet use values of each observed city, was $51.5 \%$. Helmet use rates for the different observation sites are listed in Table 1.

\subsection{Observation sites}

It can be observed that helmet use varies widely in Myanmar, ranging from an average of $26.9 \%$ in Pakokku to an average of $74.8 \%$ in Mandalay. A $\chi^{2}$ test for homogeneity revealed that helmet use differed significantly between observation sites $\left(\chi^{2}(6)=15135.13, p<.001\right)$. Through the $95 \%$ confidence interval (CI) it becomes apparent that five of the seven observation sites differ significantly in the observed helmet use, as their 95\% CI do not overlap. Only the helmet use estimates for Pakkoku and Yangon do not show this statistically significant difference. Since passengers have a lower helmet use than drivers (see 3.2.), the difference in helmet use between observation sites could be attributed to differences in driver to passenger ratios. However, the share of passengers observed at different observation sites was observed to vary little, ranging from $30.2 \%$ to $38.3 \%$ (Table 1), and did not significantly correlate with observed helmet use $(r=-.52, p=.24)$. 
Table 1. Details on observation sites, overall helmet use, and confidence intervals.

\begin{tabular}{|c|c|c|c|c|c|}
\hline $\begin{array}{c}\text { City } \\
\text { [Population] }\end{array}$ & $\begin{array}{c}\text { Recording } \\
\text { duration } \\
\text { [hh:mm:ss] }\end{array}$ & $\begin{array}{l}\text { Coded } \\
\text { riders }\end{array}$ & $\begin{array}{l}\text { Helmet use (\%) } \\
\quad(95 \% \mathrm{Cl})\end{array}$ & $\begin{array}{c}\text { Share of } \\
\text { passengers of } \\
\text { all riders (\%) }\end{array}$ & $\begin{array}{c}\text { Riders not } \\
\text { recognized } \\
(\%)^{*}\end{array}$ \\
\hline $\begin{array}{c}\text { Bago } \\
{[254,424]}\end{array}$ & $46: 51: 48$ & 18,887 & $\begin{array}{c}55.4 \% \\
(54.7 \%-56.1 \%)\end{array}$ & $30.2 \%$ & $3.0 \%$ \\
\hline $\begin{array}{l}\text { Mandalay } \\
{[1,225,546]}\end{array}$ & $164: 28: 59$ & 64,591 & $\begin{array}{c}74.8 \% \\
(74.4 \%-75.1 \%)\end{array}$ & $31.4 \%$ & $3.1 \%$ \\
\hline $\begin{array}{l}\text { Naypyitaw } \\
{[333,506]}\end{array}$ & 31:52:39 & 3,343 & $\begin{array}{c}64.5 \% \\
(62.9 \%-66.1 \%)\end{array}$ & $30.2 \%$ & $3.5 \%$ \\
\hline $\begin{array}{c}\text { Nyaung-U } \\
{[48,528]}\end{array}$ & 24:30:07 & 11,862 & $\begin{array}{c}51.2 \% \\
(50.3 \%-52.1 \%)\end{array}$ & $32.7 \%$ & $1.4 \%$ \\
\hline $\begin{array}{l}\text { Pakokku } \\
{[90,842]}\end{array}$ & $48: 56: 13$ & 17,802 & $\begin{array}{c}26.9 \% \\
(26.3 \%-27.6 \%)\end{array}$ & $30.4 \%$ & $0.5 \%$ \\
\hline $\begin{array}{l}\text { Pathein } \\
{[169,773]}\end{array}$ & 40:53:49 & 7,194 & $\begin{array}{c}60.0 \% \\
(58.9 \%-61.2 \%)\end{array}$ & $31.4 \%$ & $8.1 \%$ \\
\hline $\begin{array}{l}\text { Yangon } \\
\text { (suburban) } \\
{[4,728,524]}\end{array}$ & $16: 30: 04$ & 1,105 & $\begin{array}{c}27.9 \% \\
(25.2 \%-30.5 \%)\end{array}$ & $38.3 \%$ & $4.8 \%$ \\
\hline
\end{tabular}

*due to occlusion of the camera through weather

\subsection{Number of passengers \& position on the motorcycle}

As the number of riders on each motorcycle was registered in this study, a binary logistic regression was calculated to investigate the relation between the number of riders on a motorcycle and their helmet use. The regression revealed that helmet use decreases significantly for additional riders on the motorcycle $\left(\chi^{2}(5)=6785.55, p<.01\right)$. Motorcycles with only one rider (the driver) had a helmet use rate of $71.8 \%$ while motorcycles with two riders (driver plus on passenger) had a helmet use of $57.9 \%$. Helmet use further decreased for additional riders (Table 2). Calculating the number of helmets per motorcycle, it becomes apparent that the number of helmets per motorcycle is close to 1, irrespective of the number of 
riders. This could be attributed to the driver of the motorcycle wearing the sole helmet, while additional riders do not wear a helmet. Looking at the drivers share of helmet use for motorcycles with more than one rider, it becomes clear that this is not the case. While $100 \%$ of helmet use of motorcycles with only one rider can be attributed to the driver, this share drops to approximately $50 \%$ once there is more than one rider of the motorcycle (Table 2).

Table 2. Helmet use and odds ratios for different numbers of riders on the motorcycle

\begin{tabular}{|c|c|c|c|c|c|c|}
\hline $\begin{array}{l}\text { Number } \\
\text { of riders }\end{array}$ & $\begin{array}{c}\text { Motorcycles } \\
\text { observed }\end{array}$ & $\begin{array}{c}\text { Helmet } \\
\text { use }\end{array}$ & $\begin{array}{c}\text { Helmets } \\
\text { per } \\
\text { motorcycle }\end{array}$ & $\begin{array}{c}\text { Helmet use } \\
\text { attributed to } \\
\text { drivers }\end{array}$ & $\begin{array}{l}\text { Odds ratio } \\
\text { (compared } \\
\text { to } 1 \text { rider) }\end{array}$ & $95 \% \mathrm{Cl}$ \\
\hline 1 & 50,492 & $71.8 \%$ & 0.72 & $100.0 \%$ & 1 & \\
\hline 2 & 31,842 & $57.9 \%$ & 1.16 & $55.3 \%$ & $0.54^{* *}$ & $0.53-0.55$ \\
\hline 3 & 3,161 & $31.3 \%$ & 0.94 & $56.0 \%$ & $0.18^{* *}$ & $0.17-0.19$ \\
\hline 4 & 270 & $28.0 \%$ & 1.12 & $48.8 \%$ & $0.15^{\star *}$ & $0.13-0.18$ \\
\hline 5 & 7 & $17.1 \%$ & 0.86 & $50.0 \%$ & $0.08^{*}$ & $0.03-0.20$ \\
\hline
\end{tabular}

Through coding the position of riders on the motorcycle it was further possible to calculate individual helmet use for different positions (Figure 1). Generally, helmet use was higher for drivers $(68.1 \%)$ than for passengers $(46.1 \%)$. Detailed data on individual positions on the motorcycle reveals decreased helmet use of passengers at additional positions. The observed sample sizes for different positions vary widely, and some positions were not observed very often in this study (e.g. we only observed 34 riders at the passenger 3 position). Helmet use for passengers standing on the floorboard of the motorcycle, between the driver and the handle bars (position "P0"), was alarmingly low with only $11.3 \%$. In all observed cases, passengers at this position were young children. 


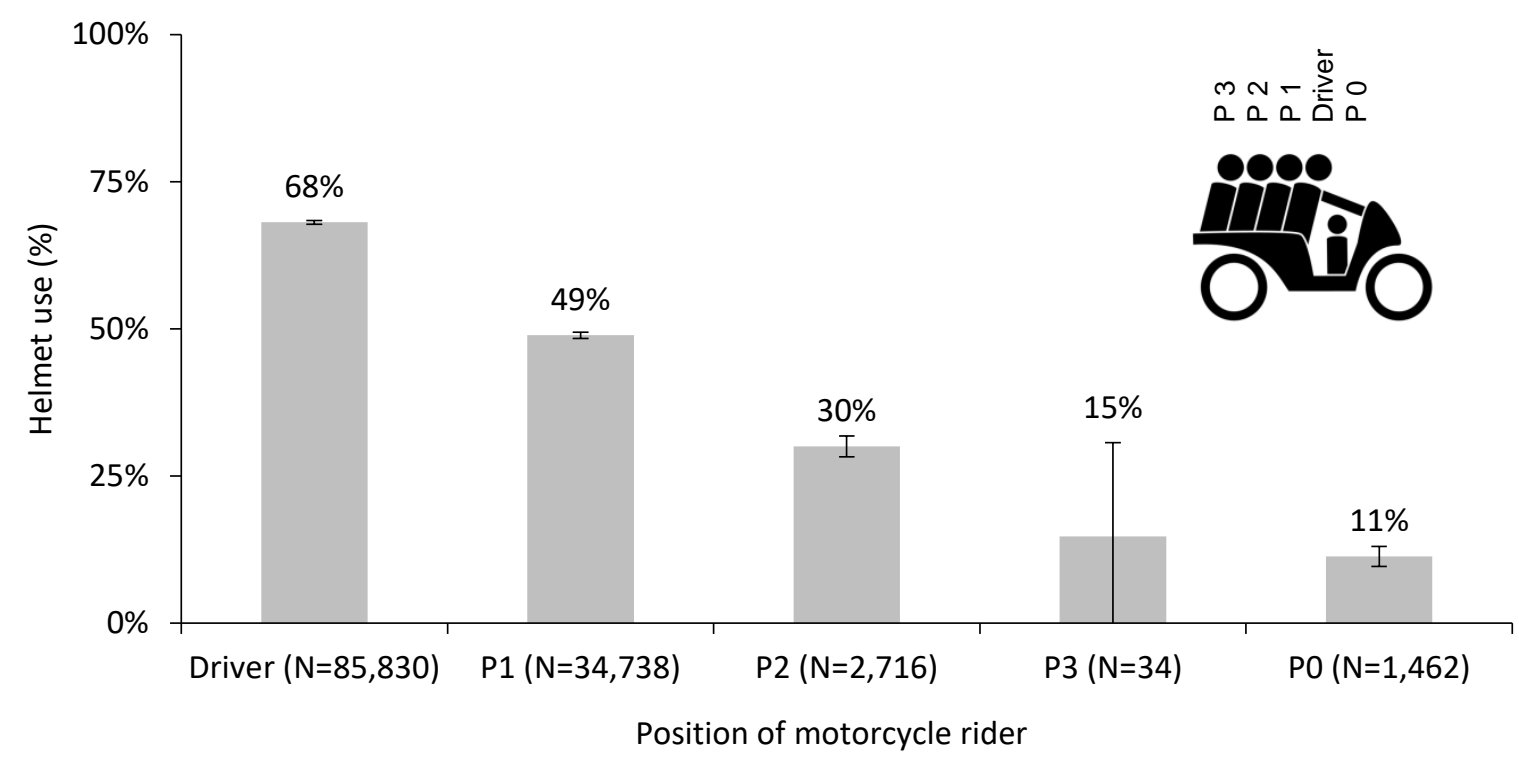

Figure 1. Average helmet use for the different positions on the motorcycle $(N=124,780)$. Passenger 0 stands on the floorboard of the motorcycle and does not sit on the seat. Error bars show the $95 \%$ confidence interval.

\subsection{Gender differences}

To keep the coding workload at a manageable level, the gender of riders was only coded for one day of observation in Mandalay. In total, 4,989 riders (1,343 female, 3,646 male) were coded for their gender. Drivers were more often male (82\%) than female (18\%), while the gender of passengers was more balanced ( $47.8 \%$ male, $52.2 \%$ female). To investigate the influence of gender on helmet use, we calculated a binary logistic regression. Overall, helmet use was significantly higher for female riders $(81.8 \%)$ than for male riders $(77.9 \%)$ (Odds Ratio $(O R)=0.79, p<.01)$. Female drivers had a significantly higher helmet use rate $(90.6 \%)$ than male drivers $(82.6 \%)(O R=0.49, p<.01)$. This difference in helmet use was even larger for passenger positions on the motorcycle, where female passengers used a helmet in $73.2 \%$ and male passengers used a helmet in only $55.2 \%$ of observations $(O R=0.45, p<.01)$. 


\subsection{Helmet use variation throughout the day}

Apart from differences between observation sites, different numbers and positions of riders on the motorcycle, and gender, it was observed that helmet use varies throughout the day. Average helmet use for every observed hour during the day is plotted in Figure 2, together with the average number of riders per motorcycle. Average helmet use is lowest at 6am, the beginning of each observation period. Helmet use then increases during the morning hours, and levels off after reaching its highest value at 10am. A sharp decrease in helmet use can be observed at $6 \mathrm{pm}$, the end of the observation period. This pattern can be observed at each individual observation site, the maximum helmet use rates was always observed between 9am and $2 \mathrm{pm}$, while lowest helmet use before this peak is registered at 6am and lowest helmet use after this peak is registered at $5 \mathrm{pm}$ or $6 \mathrm{pm}$. As helmet use is influenced by the number of riders on the motorcycle (see 3.2.), the average number of riders on a motorcycle at a given time could influence helmet use. In this case, helmet use and number of riders would be negatively correlated, as a high number of passengers would be accompanied by lower helmet use. However, a Pearson correlation shows no significant relation between helmet use throughout the day and the average number of riders per motorcycle $(r=.19, p=.53)$. A regression analysis with a linear model does not show a significant linear relation between time of day and helmet use $\left(r^{2}=.03, F_{(1,11)}=.31, \mathrm{p}=.59\right)$. Since Figure 2 descriptively shows a reversed u-shape relation between time of day and helmet use, we calculated a curvilinear regression analysis with a quadratic model. The curvilinear regression reveals a significant relation between helmet use and time of day, and explains more variance than a linear regression $\left(r^{2}=.73, F_{(2,10)}=13.42, p<.01\right)$. 


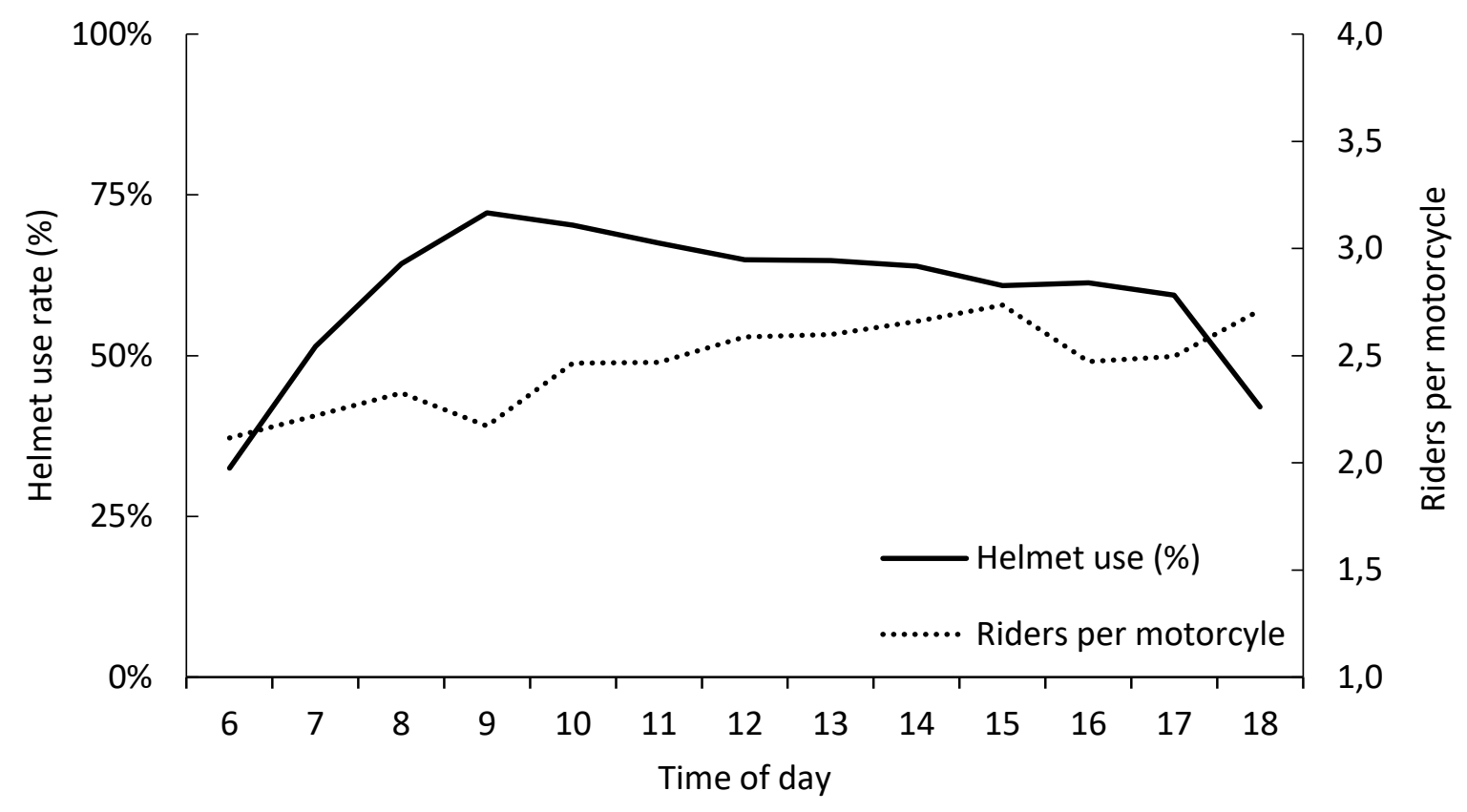

Figure 2. Average helmet use rate and riders per motorcycle throughout the day.

\subsection{Helmet use on holidays}

To investigate the influence of a national holiday on helmet use of motorcyclists, traffic was recorded for seven consecutive days in Mandalay. Average helmet use during this week is plotted in Figure 3 together with the absolute number of observed riders per day. 


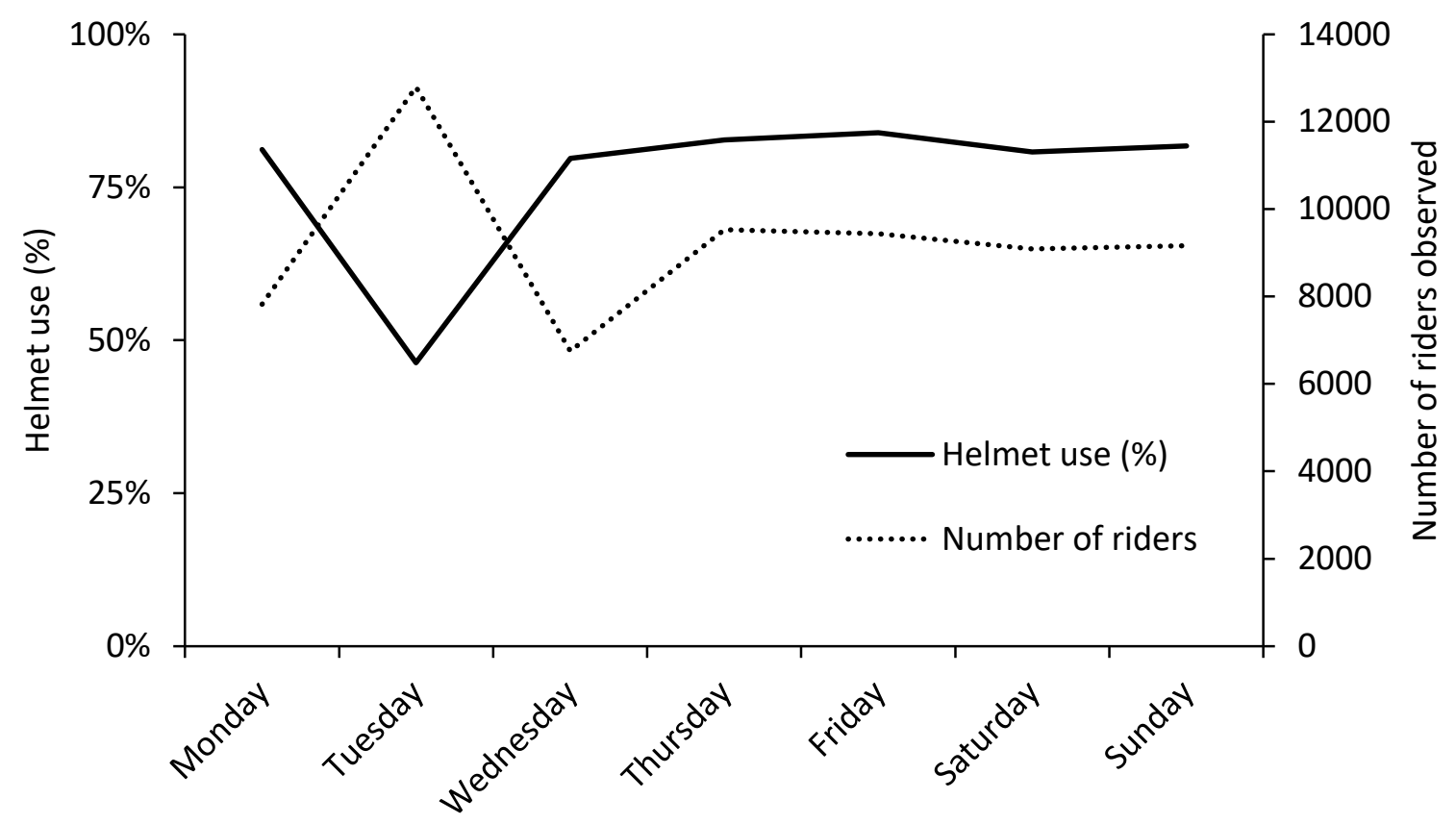

Figure 3. Average helmet use and absolute number of riders observed during one week in Mandalay $N=64,591)$.

Helmet use in Mandalay decreases on Tuesday 19th of July 2016, where it is observed to be only $46.3 \%$ compared to an average of $81.7 \%(S D=1.4 \%)$ during the rest of the week. A $\chi^{2}$ test revealed that this difference is significant $\left(\chi^{2}(1)=6843.91, p<.001\right)$. While helmet use decreases, the number of riders increases on the 19th of July and is almost $50 \%$ higher than during the rest of the week. The absolute number of riders is found to significantly correlate negatively with helmet use throughout the week $(p=-.79, p=.03)$. It is important to note that the decrease in helmet use on the 19th of July 2016 can be observed in drivers as well as in passengers. Driver helmet use drops by $30.2 \%$ (from $86.8 \%(S D=1.3 \%$ ) during the rest of the week to $56.6 \%$ on the 19 th), while passenger helmet use drops by $34.2 \%$ (from $68.3 \%$ (SD = $2.4 \%$ ) to $34.1 \%)$ 


\section{DISCUSSION}

The observation of motorcycle riders in Myanmar revealed multiple patterns of helmet use. We found that drivers have a higher helmet use rate than passengers, which corroborates findings from other low- and middle-income countries (World Health Organization, 2015). Our results expand these findings, as we found that helmet use decreases for every additional passenger on the motorcycle. These results underline the importance of the effort by the WHO to list separate numbers for driver and passenger helmet use in the Global Status on Road Safety to arrive at a more accurate evaluation of motorcycle helmet use (World Health Organization, 2015). Irrespective of the number of passengers, the number of helmets per motorcycle stays close to one. Apart from stronger police enforcement of existing helmet laws, regulation for the compulsory purchase of at least two helmets with each motorcycle purchase could help to increase helmet use among passengers. Female riders had a higher helmet use rate than male riders, regardless of their position on the motorcycle. This finding contributes to the majority of previous research which found similar effects (Li et al., 2008; Skalkidou et al., 1999; Xuequn et al., 2011). It is important to note that studies in Vietnam showed an influence of rider position on this gender effect (Hung et al., 2006) which was not found in Myanmar. Helmet use was observed to be lowest in the early morning and late afternoon, and highest between 9am and 2pm. The decrease of motorcycle helmet use at the beginning and the end of the working day mirrors earlier research results from other developing countries ( $\mathrm{Li}$ et al., 2008). A relation between helmet use and police working hours might help to explain the variance in helmet use throughout the day. A possible way to counteract this pattern would be to conduct helmet use enforcement outside of the usual police working hours to achieve constantly high helmet use. However, since this study was observational in nature, a direct influence of police enforcement on motorcycle helmet use can only be assumed. 
For motorcycle helmet use determination and reporting in the Decade of Action for Road Safety, the high variance between different observation sites underlines the importance of collecting comprehensive, multi-city data. It is not enough to assess motorcycle helmet use of a country in only one city. A multi-city base for a helmet use estimate has the added benefit that cities with a relatively high helmet use can serve as a model for traffic law enforcement and traffic safety education in other cities. Since motorcycle helmet use varies not only between different cities, but also throughout the day, rigorous collection and reporting guidelines are necessary. Therefore, the authors of this study recommend that easy to follow collection and reporting guidelines for motorcycle helmet use are developed, to facilitate comprehensive and rigorous data collection.

For Myanmar this study reveals an alarmingly low overall motorcycle helmet use rate of only $51.5 \%$. This low number should be a call to action for road safety actors in the country to strengthen the enforcement of existing road safety legislation. It is important to note that due to the high variance in helmet use in Myanmar, there are cities with a relatively high helmet use rate. Mandalay especially, with its helmet use rate of $74.8 \%$, can be used as a role model for traffic safety campaigns and police enforcement in other cities in the country. Conversely, more research on reasons for non-helmet use is needed in cities with a relatively low helmet use rate. Besides a generally lower helmet use of passengers, children at the "Passenger 0" position (Figure 1) were found to wear helmets in only $11 \%$ of observations in Myanmar. Targeted road safety education in schools has been proven to be effective in increasing helmet use among children in the past, and should be established in Myanmar (Ederer et al., 2015). Another critical finding is the decline of helmet use during the national holiday in Mandalay that is accompanied by an increase in motorcycle traffic. From this study it is not clear what the mechanism behind this effect is. Low helmet use could either be caused by motorcycle riders that do not use their motorcycles regularly and are therefore less likely to use a helmet, or by lower police enforcement, as the police force has other main objectives on this day. A 
questionnaire survey of Myanmar motorcycle riders is needed to find the causes of helmet use decline on national holidays.

For road safety researchers in other countries, this study forms a promising methodological basis for helmet use research. Many developing countries are facing the challenge of rapid motorization, and often have little resources for investigating helmet use. Through the use of low-cost cameras, helmet use data can be collected in countries with little resources. Using existing traffic surveillance infrastructure, such as CCTV, could further decrease the cost and allow for periodic surveys of helmet use. Assessing helmet use through video-based observation generates more accurate data and is more cost-effective than e.g. hospital based helmet use assessment. The authors of this study hope that similar studies in other countries can help to improve the knowledge base on helmet use in low- and middle-income countries.

In future studies, observational data collection should be accompanied by a questionnaire survey, especially in the light of results that show a significant influence of individual riders' motivations on helmet use (discussed in section 1.1.). Motivational data on helmet use can form the basis for targeted helmet use campaigns and needs to accompany police enforcement campaigns. Furthermore, the potential influence of temperature and precipitation on helmet use should be researched, either through weather sensors directly at observation sites or (if available) through detailed data from nearby weather stations. The alarmingly low helmet use of children needs to be researched further. Potential explanations, such as the unavailability of child helmets or parents avoiding to buy child-size helmets until their children are older (so they do not outgrow them) need to be researched in more detail. Our results on the relation between helmet use and time of day underscore the need to investigate the role of police enforcement, e.g. by tracking the frequency of police presence around observation sites or between different observation sites. 


\section{REFERENCES}

Aghamolaei, T., Tavafian, S. S., \& Madani, A. (2011). Prediction of helmet use among Iranian motorcycle drivers: an application of the health belief model and the theory of planned behavior. Traffic injury prevention, 12(3), 239-243.

Assembly of the Union of Myanmar. (2015) 2015 Motor Vehicle Law. Retrieved from http://www.myanmarrtad.com/?q=my/download/file/fid/62.

Bachani, A. M., Branchini, C., Ear, C., Roehler, D. R., Parker, E. M., Tum, S., Ballesteros, M.F., \& Hyder, A. A. (2013). Trends in prevalence, knowledge, attitudes, and practices of helmet use in Cambodia: results from a two year study. Injury, 44, S31-S37.

Bachani, A. M., Tran, N. T., Sann, S., Ballesteros, M. F., Gnim, C., Ou, A., Sem, P., Nie, X., \& Hyder, A. A. (2012). Helmet use among motorcyclists in Cambodia: a survey of use, knowledge, attitudes, and practices. Traffic injury prevention, 13(sup1), 31-36.

Eby, D. W. (2011). Naturalistic observational field techniques for traffic psychology research. Handbook of Traffic Psychology. Academic Press, London, 61-72.

Ederer, D. J., Van Bui, T., Parker, E. M., Roehler, D. R., Sidik, M., Florian, M. J., Kim, P., Sim, S., \& Ballesteros, M. F. (2015). Helmets for Kids: evaluation of a school-based helmet intervention in Cambodia. Injury prevention, 2016; 22:52-58.

Friard, O., \& Gamba, M. (2016). BORIS: a free, versatile open-source event-logging software for video/audio coding and live observations. Methods in Ecology and Evolution, 7(11), 13251330.

Haqverdi, M. Q., Seyedabrishami, S., \& Groeger, J. A. (2015). Identifying psychological and socio-economic factors affecting motorcycle helmet use. Accident Analysis \& Prevention, 85, 102-110.

Hung, D. V., Stevenson, M. R., \& Ivers, R. Q. (2006). Prevalence of helmet use among motorcycle riders in Vietnam. Injury prevention, 12(6), 409-413.

Ichikawa, M., Chadbunchachai, W., \& Marui, E. (2003). Effect of the helmet act for motorcyclists in Thailand. Accident Analysis \& Prevention, 35(2), 183-189.

Li, L. P., Li, G. L., Cai, Q. E., Zhang, A. L., \& Lo, S. K. (2008). Improper motorcycle helmet use in provincial areas of a developing country. Accident Analysis \& Prevention, 40(6), $1937-$ 1942.

Liu, B. C., Ivers, R., Norton, R., Boufous, S., Blows, S., \& Lo, S. K. (2004). Helmets for preventing injury in motorcycle riders. The Cochrane Library.

Mathur, A. K., Gupta, S., \& Bandhu, A. (2017). A Baseline Study on Pattern of Helmet Use in the State of Rajasthan, India. Journal of Health Management, 19(3), 417-434.

Myanmar Road Transport Administration Department. (2016, June). Vehicle Information. Retrieved from http://www.myanmarrtad.com/?q=en/article/68.

Nakahara, S., Chadbunchachai, W., Ichikawa, M., Tipsuntornsak, N., \& Wakai, S. (2005). Temporal distribution of motorcyclist injuries and risk of fatalities in relation to age, helmet 
use, and riding while intoxicated in Khon Kaen, Thailand. Accident Analysis \& Prevention, 37(5), 833-842.

Nantulya, V. M., \& Reich, M. R. (2002). The neglected epidemic: road traffic injuries in developing countries. BMJ: British Medical Journal, 324(7346), 1139.

Özkan, T., Lajunen, T., Doğruyol, B., Yıldırım, Z., \& Çoymak, A. (2012). Motorcycle accidents, rider behaviour, and psychological models. Accident Analysis \& Prevention, 49, 124-132.

Otte, D., Jänsch, M., \& Haasper, C. (2012). Injury protection and accident causation parameters for vulnerable road users based on German In-Depth Accident Study GIDAS. Accident Analysis \& Prevention, 44(1), 149-153.

Oxley, J., O'Hern, S., \& Jamaludin, A. (2018). An observational study of restraint and helmet wearing behaviour in Malaysia. Transportation Research Part F: Traffic Psychology and Behaviour, 56, 176-184.

Peden, M. (2004). World report on road traffic injury prevention. World Health Organization.

Peltzer, K., \& Pengpid, S. (2014). Helmet use and associated factors among motorcyclists in the Association of Southeast Asian Nations: Prevalence and effect of interventions. African Safety Promotion: A Journal of Injury and Violence Prevention, 12(1), 72-86.

Skalkidou, A., Petridou, E., Papadopoulos, F. C., Dessypris, N., \& Trichopoulos, D. (1999). Factors affecting motorcycle helmet use in the population of Greater Athens, Greece. Injury prevention, 5(4), 264-267.

United Nations (2010). General Assembly resolution 64/255, Improving global road safety, A/64/L.44, available from http://undocs.org/A/RES/64/255.

United Nations (2015). General Assembly resolution 70/1, Transforming our world: the 2030 Agenda for Sustainable Development, A/70/L.1, available from http://undocs.org/A/RES/70/1.

Vos, T., Abajobir, A.A., Abbafati, C., Abbas, K.M., Abate, K.H., Abd-Allah, F., ... Murray, C.J.L. (2017). Global, regional, and national incidence, prevalence, and years lived with disability for 328 diseases and injuries for 195 countries, 1990-2016: a systematic analysis for the Global Burden of Disease Study 2016. The Lancet, 390(10100), 1211-1259.

Wegman, F., Watson, B., Wong, S.V., Job, S., Segui-Gomez, M. (2017). Road Safety in Myanmar. Recommendations of an Expert Mission invited by the Government of Myanmar and supported by the Suu Foundation. Paris, FIA.

World Health Organization. (2006). Helmets: a road safety manual for decision-makers and practitioners. World Health Organization.

World Health Organization. (2015). Global status report on road safety 2015. World Health Organization.

World Health Organization. (2017). Powered two- and three-wheeler safety: a road safety manual for decision-makers and practitioners. World Health Organization. 
Xuequn, Y., Ke, L., Ivers, R., Du, W., \& Senserrick, T. (2011). Prevalence rates of helmet use among motorcycle riders in a developed region in China. Accident Analysis \& Prevention, 43(1), 214-219. 